\title{
Diet and habitat affinities in six raptor species in India
}

\author{
Satish Pande ${ }^{1,2}$, Reuven Yosef ${ }^{2,3^{*}}$ (D) Federico Morelli ${ }^{4}$, Rajkumar Pawar ${ }^{1}$ and Ram Mone ${ }^{1}$
}

\begin{abstract}
Background: Sympatric species adapt to, and temporally or geographically segregate access to similar limiting factors.

Methods: We compared nesting habitat and diet affinities of six raptor species in central India between the years 2006-2015.

Results: A large composition of reptiles in the diet was characteristic for Circaetus gallicus, Spilornis cheela and Elanus caeruleus, while Aquila fasciata, Falco chicquera and Nisaetus cirrhatus show a higher proportion of birds. Species with greatest similarity of diet were C. gallicus and S. cheela. Considering the environmental characterization of areas where raptors built the nest, some species were ecologically closer than others. N. cirrhatus and S. cheela were related to the presence of water bodies, dry deciduous forest and evergreen forests, while E. caeruleus and C. gallicus preferred more open habitats. A. fasciata bred either on cliffs or trees, F. chicquera on trees or mobile towers, and the other four species built their nests exclusively in trees.
\end{abstract}

Conclusions: We conclude that although there was overlap in diet and nesting ecology for a number of species, the geographical separation likely limits competition for resources.

Keywords: Raptor species, Diet, Breeding area, Niche overlap, Resource partitioning

\section{Background}

Diet and habitat suitability can be considered as dimensions of a species' niche wherein individuals can subsist in the presence of inter-, intra-specific competition and other ecological pressures (Schoenert 1974). Apex-predators that overlap in their ecological requirements and coexist in the same area are usually prone to continuous competition between the two or more species and usually is to the detriment of the inferior of the competitors (e.g., Common Leopard Panthera pardus, Bengal Tiger P. tigris; Lovari et al. 2015; raptors; Sarà et al. 2016). Raptors, also considered to be apex predators in their respective food chains, are considered to be excellent bioindicators of ecosystem imbalances (e.g., Jiménez et al. 2007) that are usually to be found in relatively low numbers in any given habitat, and compared to their

\footnotetext{
*Correspondence: ryosef60@gmail.com

${ }^{3}$ Ben Gurion University of the Negev-Eilat Campus, P. O. Box 272, 88000 Eilat, Israel

Full list of author information is available at the end of the article
}

prey will almost always have low reproductive rates (Bildstein 2006). The understanding of the coexistence, biotic interactions and ecological affinities of raptor species, is necessary in order to optimize management planning of those species, enhancing potentially their conservation in nature (Sanchez-Zapata et al. 2003; Sarà et al. 2016).

Sergio et al. (2005) considered it imperative to establish conservation sites in order to be able to conserve biodiversity. However, they also realized that even managing conservation areas can be tricky because not all species can be favoured or considered to be of conservation priority, and once a priority decision has been made, not all species will profit from it. Similarly, if the species of concern are wide ranging, have large territories, and with a wide prey base, like most raptors, their conservation becomes problematic (cf. Ferrer 2001). This is especially exacerbated when no such reserves exist and the wild populations have to contend with anthropogenic expansions (Allan et al. 2017). This paper is one such case-study of six raptor species that coexist without, and 
outside, nature reserves and in the proximity of unrestrained human activities.

The aim of this study was to compare the resource affinities of six raptor species in the western part of central India, on the basis of their diet and environmental composition of the habitat occupied by each species. We realize that we are going to analyse species with different body-size and ecology and that it is unlikely that the two small species can compete with the larger species. The first assembly rule in communities happens by size and small raptors can coexist with large ones by having totally different ecological niches and resource choices (see Hakkarainen et al. 2004). In addition, small raptors can decide to coexist with large ones to get protection from a suite of other predators (cf. Lima and Dill 1990), even paying the potential cost due to the risk of being hit or predated upon by the protector (Rebollo et al. 2017).

We wished to elucidate the regional coexistence, and possible resource overlap of the six raptor species studied. Rebollo et al. (2017) contended that analyzing the spatial distribution of predators in the same guild has theoretical and applied value because it provides insights into predator-prey systems and mechanisms of predator coexistence that are more realistic and integrated than insights gained from mono-specific approaches. This study is of much importance because of the fast pace of anthropogenic-related development of wild and semiagricultural areas, especially in India.

\section{Methods}

The study was conducted in Maharashtra State, Central India (Fig. 1). Data on the six raptor species were collected between the years 2006-2015 during the breeding season only, December-May, by ornithological teams of the ELA Foundation, a non-profit NGO from Pune. We hypothesized that as the breeding season commences the raptors are likely to increase their resource demand and was likely to increase competition for resources.

The raptor species included in the study were Blackshouldered Kite (Elanus caeruleus, $n=11$ territories), Short-toed Eagle (Circaetus gallicus, $n=9$ ), Crested Serpent Eagle (Spilornis cheela, $n=14$ ), Bonelli's Eagle (Aquila fasciata, $n=28$ ), Changeable Hawk-eagle (Nisaetus cirrhatus, $n=14$ ), and Red-necked Falcon (Falco chicquera, $n=15)$. Except for Falco chicquera, all of the raptors are classified as of least concern and common

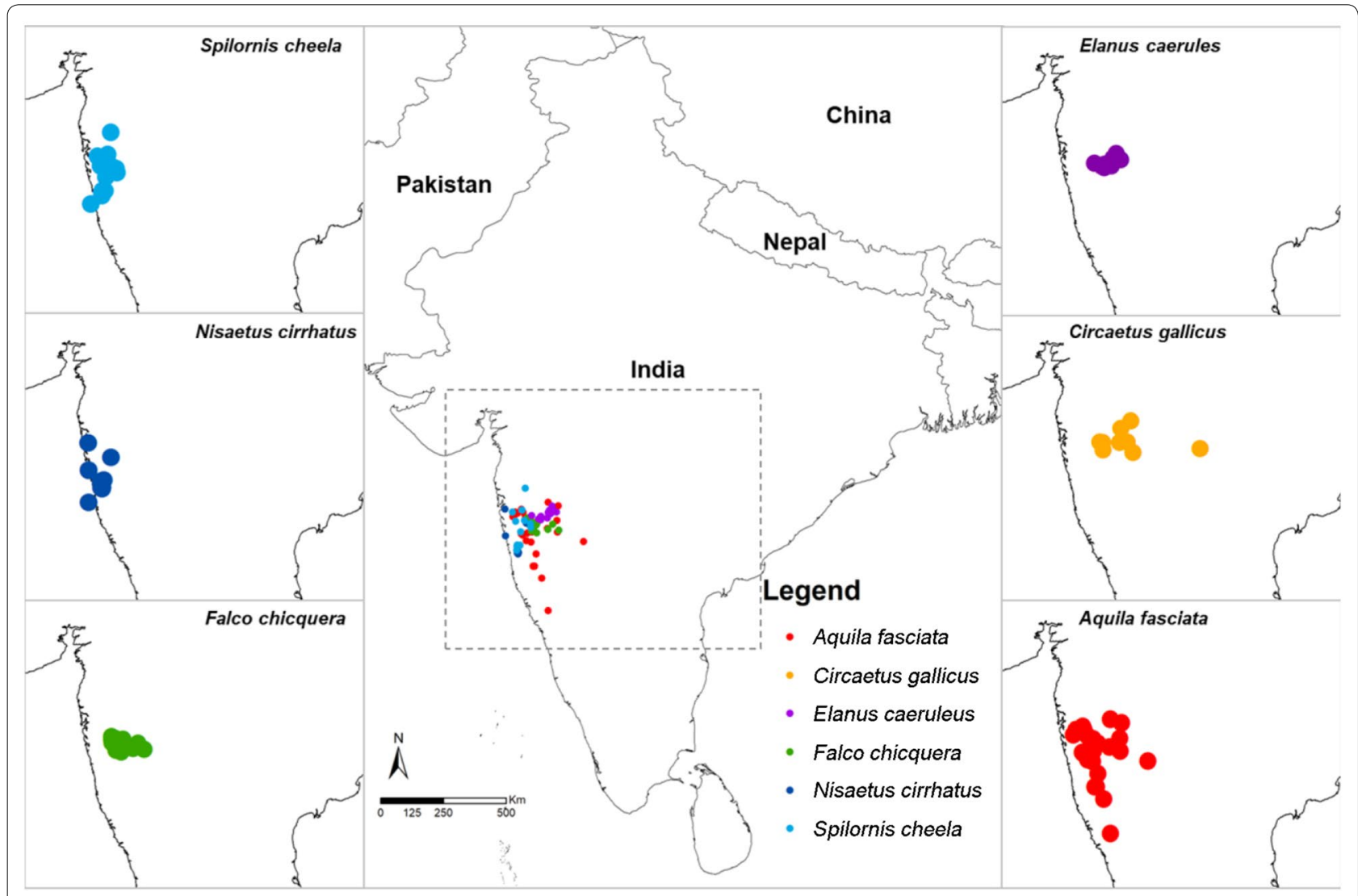

Fig. 1 Location of 91 nesting sites of six raptor species surveyed in west-central India, included in this study 
throughout most of the Indian sub-continent and their breeding range (Naoroji 2006). Falco chicquera is classified as Near Threatened and is reported to have disappeared from many parts of India, in what is perceived as an overall decline (Birdlife International 2016).

For all pairs of each of the studied raptor species, we also collected information on diet composition (number of prey classified as an insect, reptile, small bird, large bird, small mammal, or large mammal) both by direct observations and collecting and analysing pellets at the nest and its immediate environs. Prey were identified using published literature (Tikader and Bastawade 1983; Tikader and Sharma 1992 see Pande et al. 2011); or by comparing with specimens in the collection of the Pune section of the Zoological Survey of India. Furthermore, an environmental description of the habitat, describing the land use composition in a radius of $5 \mathrm{~km}$ around each nest was performed by using Google Earth pictures and subsequent blind ground-proofing (cf. Kempe and Dirks 2008). Land use types were classified as agricultural, human habitation, open grassland, water body, dry deciduous forest, moist deciduous forest, evergreen forest and hills.

A principal component analysis (PCA) on a covariance matrix was used to determine which environmental characteristic (land use composition, latitude and longitude) and which prey type contributed most to variation among raptor species affinities (Janžekovi and Novak 2012).

In order to explore the differences in utilisation of resource (prey use and land use composition around breeding sites) for each raptor species, we used the niche overlap module provided in 'EcoSimR' package for (Gotelli et al. 2015) in order to plot the resource utilisation matrix. The data collected on raptor species was arranged in a matrix: the raptor species in rows, while prey consumed and land use composition around nesting site year by year in columns. This plot model provides a graphical portrayal of observed utilisation matrix. In Fig. 5, the area of each circle is proportional to the utilisation of a resource category of each species. If no circle is shown, the utilisation was zero (0).

The indices of similarity (or dissimilarity) are among the most common measures of segregation used in ecology (White 1986; Magurran 2004). The comparison among raptors species in terms of the overall affinities was performed using a similarity index. In this study, we used the function 'niche overlap' from package 'interspecies' (De Cáceres and Jansen 2016) for comparing the affinities, considering both environmental characteristics (land use composition) and diet (prey composition) for each raptor species. Function 'niche overlap' returns the overlap (especially the distance between centroids) between each pair of raptor species (De Caceres et al. 2011; De Cáceres and Jansen 2016). This value ranges from zero to one. A value of one indicates two species sharing all components with the same abundance, and a value of zero indicates two species with no components in common (Magurran 2004).

All statistical tests were performed with $\mathrm{R}$ software ( $\mathrm{R}$ Development Core Team 2017).

\section{Results}

A total of 91 raptor nests were analysed for habitat requirements (Fig. 1, Additional file 1: Fig. S1), and 3332 prey items were identified and classified into seven different groups (Additional file 1: Table S1).

The large composition of reptiles in the diet was characteristic for C. gallicus, S. cheela and E. caeruleus, while A. fasciata, F. chicquera and N. cirrhatus show a higher proportion of large and small birds (Fig. 2). The species with the greatest similarity of diet composition were $C$. gallicus and S. cheela, and to a lesser degree also A. fasciata and $N$. cirrhatus (Fig. 3). A. fasciata appears to be the most generalist of the six species and its diet was composed of almost equal proportions of all prey.

Considering the environmental characterization of areas where raptors built the nest, some species were ecologically more similar than others. N. cirrhatus and $S$. cheela nest site preferences were related to the presence of water bodies, dry deciduous forest and evergreen forests, while E. caeruleus and C. gallicus nest site preferences were related to more open habitats (Fig. 4). A. fasciata bred either on cliffs or trees, F. chicquera on trees or mobile towers, and the other four species built their nests exclusively in trees. In the PCA scores plot for the environment, PC1 accounted for $41.3 \%$ and PC2 25.4\% (Fig. 3).

The matrices of overall resources utilisation based on diet and land use composition around the nesting site for the six raptor species show a large overlap between $C$. gallicus and S. cheela, A. fasciata and N. cirrhatus, and C. gallicus and E. caeruleus (Fig. 5; Table 1).

We also observed a temporal separation in that in the study area, during the breeding season, $F$. chicquera and A. fasciata were absent in the coastal regions. This suggests a seasonal migration or dispersal of the population after the reproductive effort (unpubl. data). S. cheela is restricted to the hilly tracts of the Western Ghats while $C$. gallicus and A. fasciata are restricted to the Deccan Plateau, and were observed year round on their territories.

\section{Discussion}

One important goal of community ecology is to disentangle how communities are assembled, because the factors determining the species composition are many 


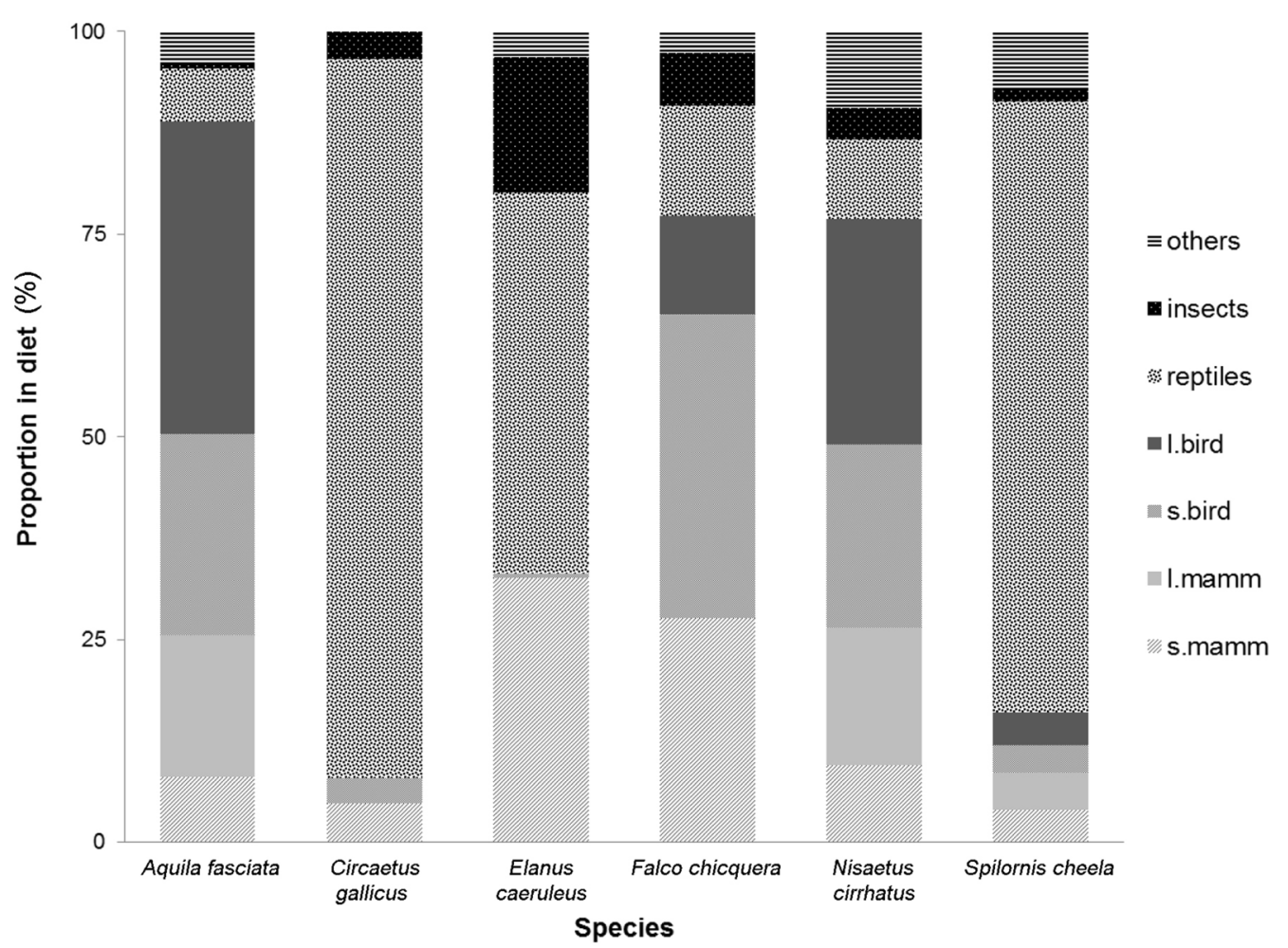

Fig. 2 The proportion in the diet of different type of prey of breeding raptor species in India, during the period 2006-2016

(Ştefănescu et al. 2013). Orians and Soulé (2001) suggested that communities are recognised as the level of ecological structure on which conservation should devote most research efforts. Hence, although our study did not concentrate on assemblages, our analyses of sixraptor species from the same ecological regions are of relevance for elucidating their respective resource exploitation and affinities, and a tool for future studies in this rapidly developing region. Our data showed that C. gallicus and $S$. cheela had the greatest similarity of diet composition and to a lesser degree also A. fasciata and $N$. cirrhatus. Differences in prey taken were evident in that the largest composition of reptiles was characteristic for C. gallicus, S. cheela and E. caeruleus, while A. fasciata, F. chicquera and $N$. cirrhatus show a higher proportion of large and small birds. However, owing to the habitat separation wherein S. cheela was found only in the hilly terrain while C. gallicus and A. fasciata on the Deccan Plateau, although we can see in the analyses diet and habitat affinities between the species, there is no real interaction between them.

Restani (1991) found that the buteo hawks partitioned habitat resources, specifically nest sites and that the species with the overlap in nesting chronology and prey use, had the least similar nest sites. Further, they found that the two species with the greatest nest substrate overlap had the lowest dietary overlap. They concluded that the diets appeared to reflect prey availability. Restani (1991) showed that the overlap in one characteristic did not mean also an overlap of other biological characteristics. Similarly, in our study, we found that although C. gallicus, $S$. cheela (predominantly large snakes) and E. caeruleus (mostly small snakes, lizards, skinks, etc.) showed greatest food niche overlap, but they built their nests in different habitats. However, one must take into account that reptiles are a diverse taxonomic group with many ecological divisions and can be exploited by a wide range of predators in the same habitat. Further, $N$. cirrhatus and $S$. cheela were related to the presence of water bodies, dry deciduous forest and evergreen forests, while E. caeruleus and C. gallicus were related to more open habitats. On a larger scale, this was also translated to geographical isolation of the nest sites.

Elucidating affinities between coexisting raptor species is of great importance for conservation in view of the constant change wrought by human expansion into wild habitats. Sanchez-Zapata et al. (2003) found that in Kazakhstan there were fewer species in agricultural habitats than in natural grassland and steppe habitats. Ground-nesting raptors were negatively affected by land use changes and four species were never detected in agricultural zones. Further, raptor abundance patterns 


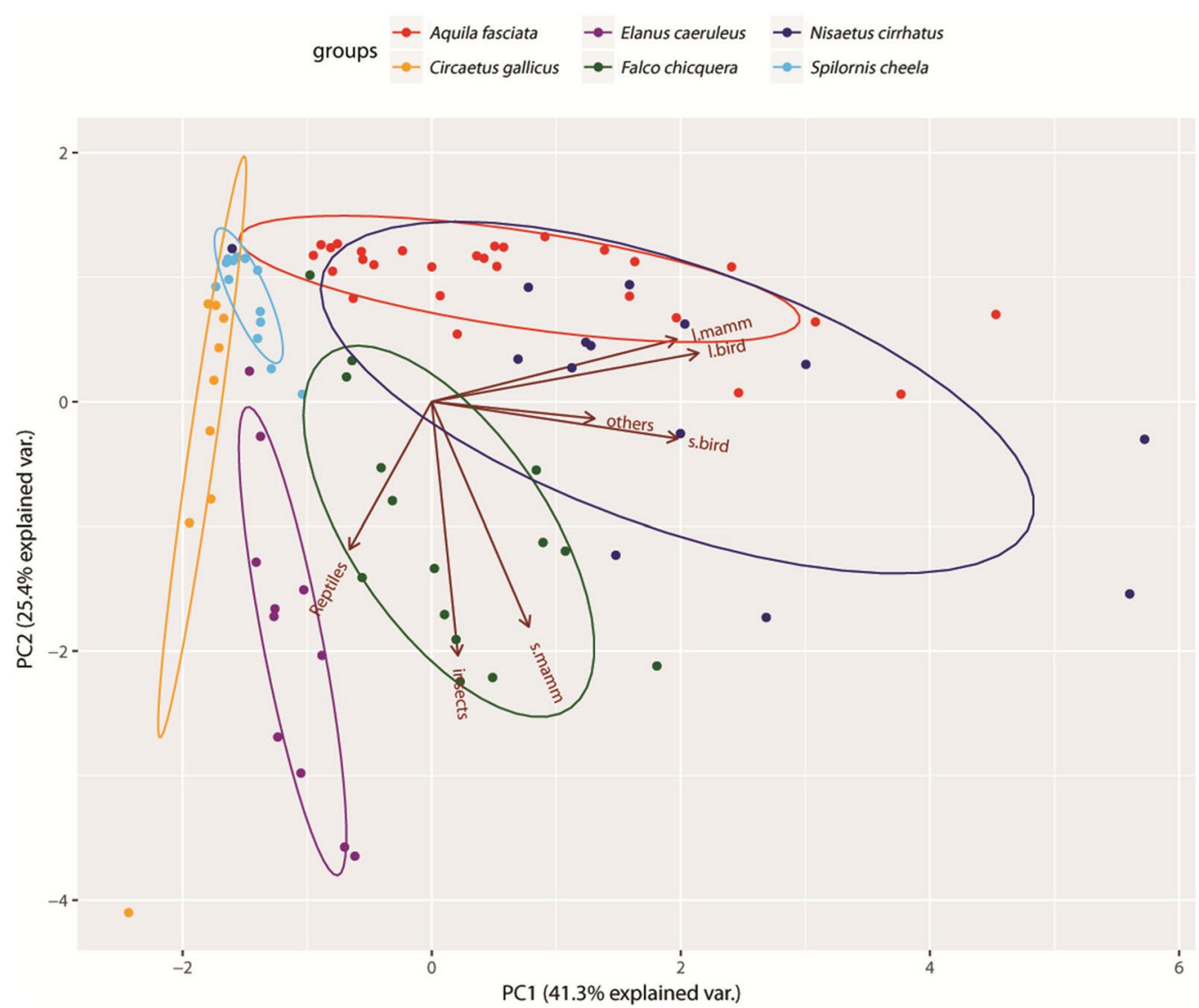

Fig. 3 Principal component analysis (PCA) of raptor species proportion in the diet of different types of prey. The colour and coloured ellipses on the scores plots denote grouping obtained from six raptor species. The proportion of variance encompassed by each principal component is given in parentheses in each axis

differed between natural steppe habitats and humantransformed habitats, where a patchy distribution was detected. Butet et al. (2010) studied the response of Common Buzzard (Buteo buteo) and Eurasian Kestrel (F. tinnunculus) in agricultural landscapes of Western France. They found that the two raptor species showed negative but differentiated response patterns to human land-use intensification and small mammal abundance. The abundance of the common buzzard decreased significantly with the reduction of hedgerows, woodlots and grasslands areas, as well as with the decrease in prey abundance at the landscape scale. They found that the abundance of the kestrel showed the same trend, but fall of abundance was less marked and resulted in a reverse ratio of species density according to agricultural intensification and landscape openness. Authors pointed out that the specific feeding habits, nesting habitats and spatial partitioning in foraging areas could explain the difference in the numerical response observed for these two raptor species. They reasoned that this was a result of the fact that buzzards forage mainly on highly profitable prey areas and avoid highly fragmented woodland habitats for nesting, in contrast to kestrels, who are able to nest in more fragmented landscapes and are better adapted to exploit less abundant but more widespread small mammal prey species within the cultivated matrix. Baladron et al. (2017) studied raptor assemblages in the flooding pampas of Argentina and concluded that several raptor species were threatened by the expansion of urban areas and agriculture. Future studies must concentrate on the influence of the expanding human population on these assemblages in order to further understand if this leads to homogenization of the populations, or to changes in their relative abundance in the region.

Until now, similar studies on raptors have not been conducted in India, a country with the second largest human population on earth. Hence, the main importance of our study is in demonstrating the degrees of nesting and diet affinities amongst six relatively common raptor species of varying sizes that are to be found in the same geographical area. This lack of knowledge is further underwritten by the fact that we have also documented 


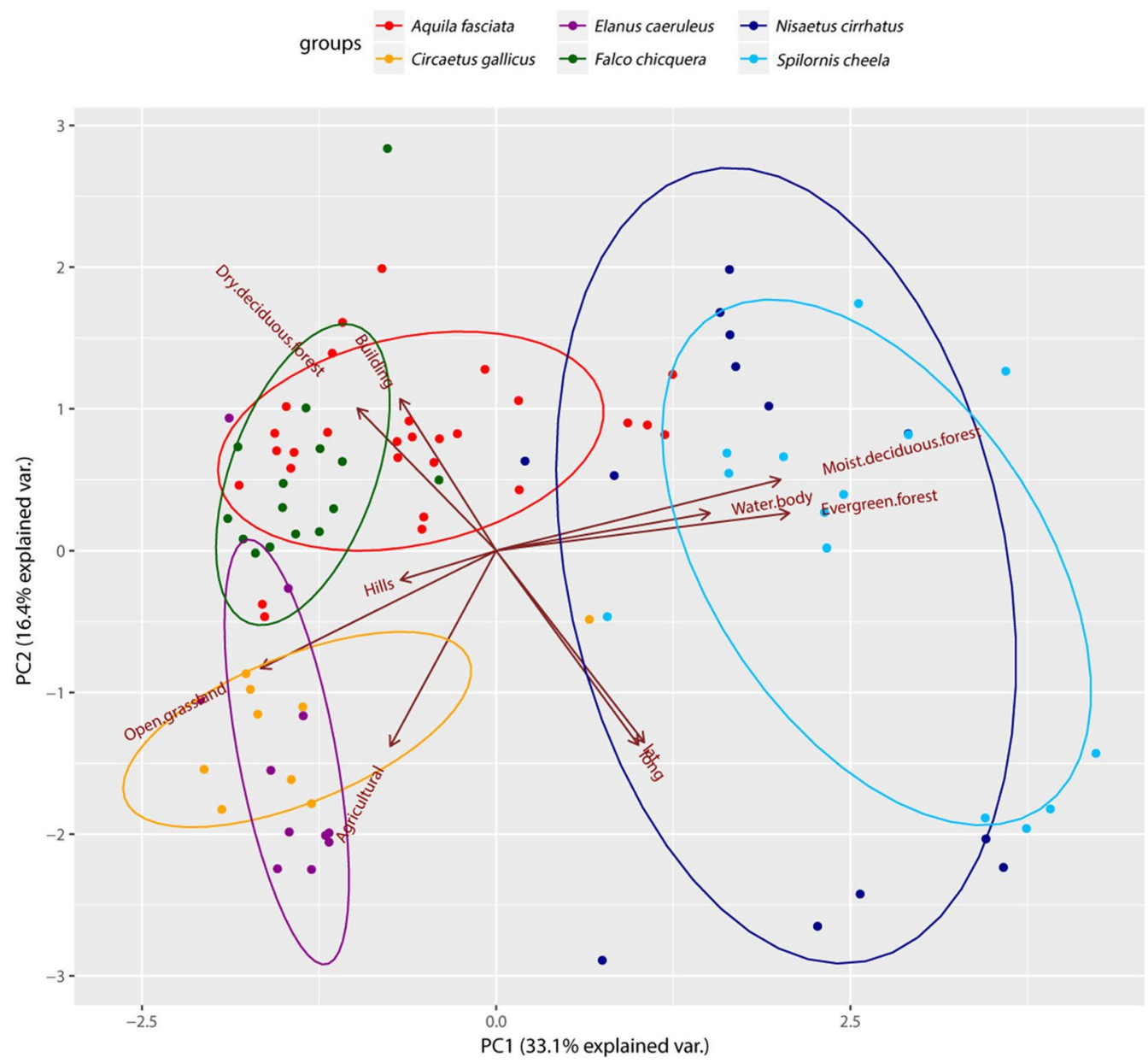

Fig. 4 Principal component analysis (PCA) of the raptor species breeding site, based on environmental composition in terms of land use, latitude and longitude. The colour and coloured ellipses on the scores plots denote grouping obtained from six raptor species. The proportion of variance encompassed by each principal component is given in parentheses in each axis

a hitherto unknown phenomenon of temporal separation wherein during the breeding season, F. chicquera and $A$. fasciata were absent in the coastal regions (unpubl. data). This suggests a seasonal migration of the population to higher breeding grounds, suggesting that further studies are required in order to ascertain the habitat connectivity of the two ranges, breeding and non-breeding, of the individuals that comprise the populations.

Jaksic and Braker (1983) found that prey taken was mainly determined by prey availability. They further found that food overlap was frequently very high, did not narrow in larger assemblages, nor was it correlated with body size. However, they found that the mean weight of prey taken was positively correlated with raptor weight within assemblages, but varied widely across assemblages, with any given species showing manifold differences. The researchers concluded that they found little support for predictions based on competition but thought that the opportunistic feeding behaviour of the raptors, and also because the food might not be a limiting resource, resulted in assemblages whose size is larger where less prey are available to per raptor species. It will be of interest to check whether in the study area, with fast human-encroachment and development, the raptor assemblage will change in the near future and conform to the conclusions of Jaksic and Braker (1983).

Divisek et al. (2014) reasoned that it is not well understood how the distribution of natural habitats affects broad-scale patterns in the distribution of animal species. They concluded that most spatial variation in the composition of assemblages of almost all animal groups probably arises from biological processes operating within a spatially structured environment and suggest that natural habitats are important to explain observed patterns because they often perform better than habitat descriptions based on remote sensing. They further state that it 


\section{Diet composition}

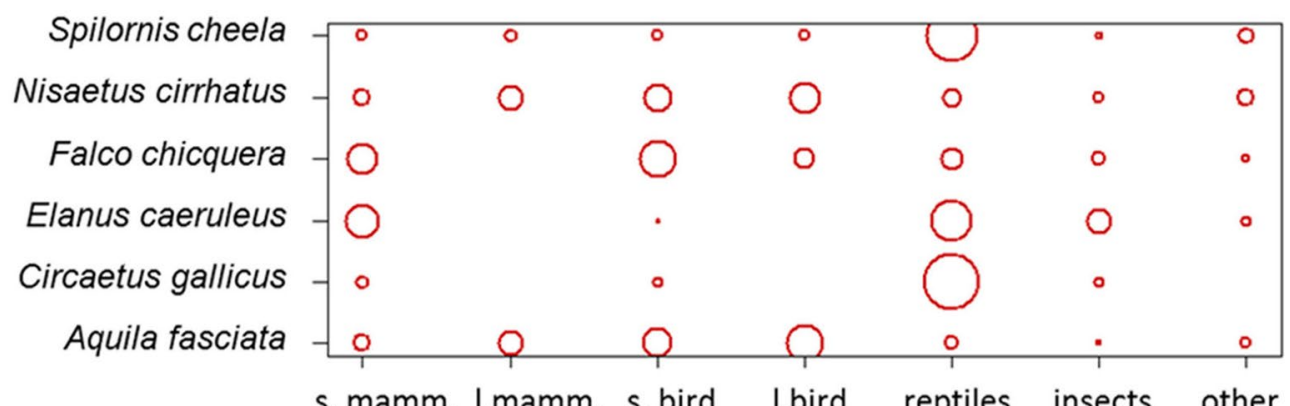

s. mamm. I.mamm. s. bird I.bird reptiles insects other

\section{Land use composition}

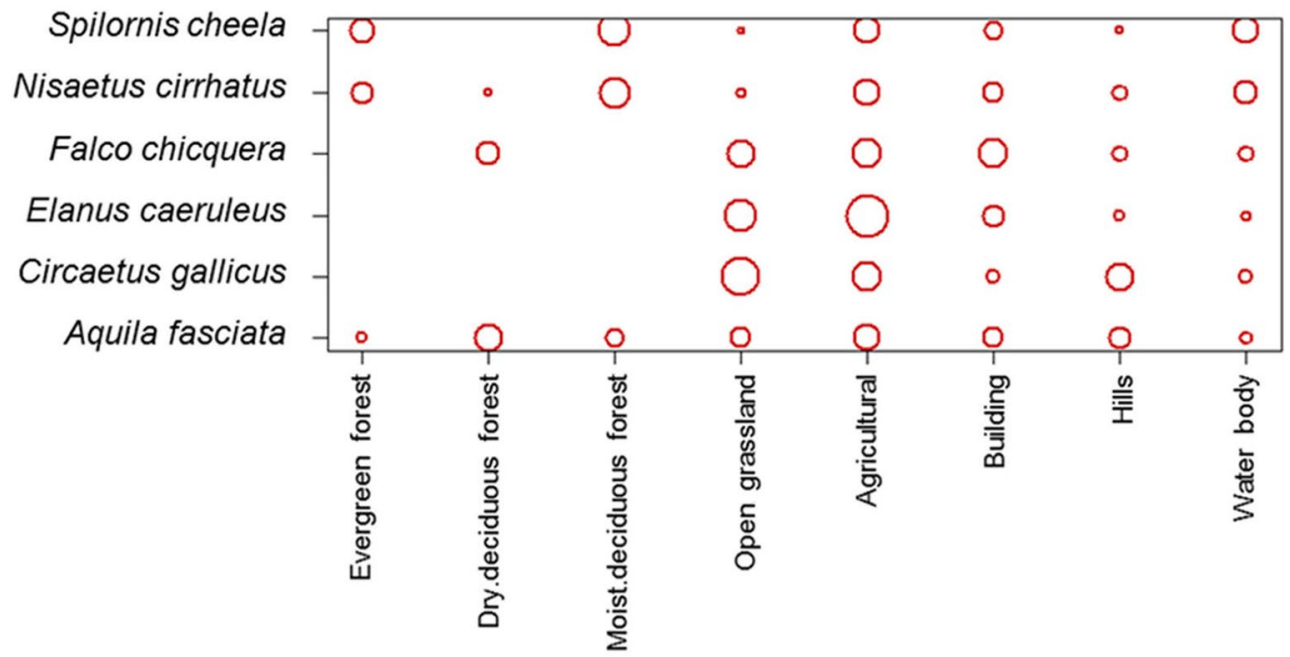

Fig. 5 Resource utilisation matrix based on diet composition and land use composition around nesting site for the six breeding raptor species in India, during the period 2006-2016. The figure provides a graphical portrayal of observed utilisation matrix, and the area of each circle is proportional to the utilisation of a resource category by each species. If no circle is shown, the utilisation was zero (0)

Table 1 Niche overlap among raptor species estimated as a similarity index based on diet composition and land use around the breeding site

\begin{tabular}{|c|c|c|c|c|c|}
\hline & $\begin{array}{l}\text { A. } \\
\text { fasciata }\end{array}$ & C.gallicus & $\begin{array}{l}\text { E. } \\
\text { caeruleus }\end{array}$ & $\begin{array}{l}\text { F. } \\
\text { chicquera }\end{array}$ & $\begin{array}{l}N . \\
\text { cirrhatus }\end{array}$ \\
\hline C. gallicus & 0.156 & & & & \\
\hline $\begin{array}{l}\text { E.caer- } \\
\text { uleus }\end{array}$ & 0.203 & 0.826 & & & \\
\hline $\begin{array}{l}\text { F.chic- } \\
\text { quera }\end{array}$ & 0.681 & 0.326 & 0.555 & & \\
\hline $\begin{array}{l}\text { N. cirrha- } \\
\text { tus }\end{array}$ & 0.972 & 0.261 & 0.341 & 0.747 & \\
\hline S. cheela & 0.228 & 0.993 & 0.820 & 0.346 & 0.340 \\
\hline
\end{tabular}

underlines the value of using appropriate habitat data, for which high-resolution and large-area field mapping projects are necessary. Most of the species in our study included a large proportion of agricultural land in their $5-\mathrm{km}$ radius home ranges. It remains unclear whether this is due to most pristine habitats being limited in availability (i.e., most have been converted to agriculture, hence it is almost a necessity that these species nest in agriculture-dominated landscapes), or alternatively, could it be that they are adaptable to anthropogenic change and may be resistant to moderate agricultural land use. This needs to be elucidated in future studies. Sadly, the fact that no such studies were undertaken on any of the study species in the past prevents a comparison with the present situation wherein continued habitat modification for humanpurposes occurs in the study area. 
Although our study encompassed a large area of Maharashtra State, the sample sizes for each of the species are limited. However, the study contributes greatly to the understanding of these raptor species and an effort needs to be made to increase the sample sizes of the assemblages greatly, and to identify a wider range of parameters within the breeding territories. These can include potential prey diversity as compared to prey hunted, or camera trapping at the nest to identify the number of prey species brought to the nest as compared to those identified in the pellets, higher resolution and relative proportions of the habitat mosaic, etc. Another aspect that needs to be studied is whether interference competition occurs within the guild (cf. Oro et al. 2009) and inter-specific resource kleptoparasitism (e.g., Hakkarainen et al. 2004; Rebollo et al. 2017).

\section{Conclusions}

In conclusion, in this study we provide new evidence about habitat and dietary affinities of six raptor species in the western part of central India. The importance of our study lies in understanding the different environmental requirements and specialisations of the different species in order to better enhance their conservation (Norris and Pain 2002). India in general, and Maharashtra State in particular, are fast-changing from being rural and with open grasslands and natural forests, to a greatly exploited region with fast development and expansion of urban areas (cf. Roychowdhury et al. 2009; Pande et al. 2017). The understanding of wildlife assemblages and guilds at the earliest is critical in order to be able to recommend appropriate conservation measures in the near future. In this regard, as highlighted in Bonaparte and Cockle (2017), it is important to work with locals to conserve species-specific niches not only in nature reserves but also in anthropogenic habitats.

\section{Additional file}

Additional file 1. Table S1. List of 91 raptor nesting sites in the study area in India and prey composition recorded for each raptor species. Figure S1. Geographical spread of six species of raptors in Western Maharashtra State, India

\section{Authors' contributions}

SP, RY conceived and designed the study; SP, RP, RM conducted fieldwork; FM performed statistical analyses; RY, FM, SP wrote the manuscript; RP, RM provided editorial advice. All authors read and approved the final manuscript.

\section{Author details}

${ }^{1}$ ELA Foundation, C-9 Bhosale Park, Sahakarnagr, Pune 411009, India. ${ }^{2}$ Department of Environmental Sciences, Savitribai Phule Pune University, Ganeshkhind, Pune 411007, India. ${ }^{3}$ Ben Gurion University of the Negev-Eilat Campus,
P. O. Box 272,88000 Eilat, Israel. ${ }^{4}$ Department of Applied Geoinformatics and Spatial Planning, Faculty of Environmental Sciences, Czech University of Life Sciences Prague, Kamýcká 129, 16500 Prague 6, Czech Republic.

\section{Acknowledgements}

Prashant Deshpande, Dr. M. N. Mahajan and Rahul Lonkar from Ela Foundation assisted in field surveys.

\section{Competing interests}

The authors declared that they have no competing interests.

\section{Consent for publication}

Not applicable.

\section{Ethics approval and consent to participate}

The study was conducted in the framework of the animal ethics rules of the Savitribai Phule Pune University. Observers did not approach nests, perched raptors or attempt to trap them.

\section{Funding}

No funding was received for conducting this study.

Received: 21 April 2018 Accepted: 22 October 2018

Published online: 29 October 2018

\section{References}

Allan JR, Venter O, Maxwell S, Bertzky B, Jones K, Shi Y, Watson JEM. Recent increases in human pressure and forest loss threaten many Natural World Heritage Sites. Biol Conserv. 2017;206:47-55.

Baladron AV, Bo MS, Bechard MJ, Malizia Al. Relative abundance, habitat use, and seasonal variability of raptor assemblages in the flooding Pampas of Argentina. J Raptor Res. 2017;51:38-49.

Bildstein KL. Migrating raptors of the world-their ecology and conservation. Ithaca: Cornell University Press; 2006.

BirdLife International. Falco chicquera. The IUCN red list of threatened species 2016. 2016:eT22727778A94961899. Downloaded on 23 December 2017.

Bonaparte EB, Cockle KL. Nest niche overlap among the endangered Vinaceous-breasted Parrot (Amazona vinacea) and sympatric cavity-using birds, mammals, and social insects in the subtropical Atlantic Forest, Argentina. Condor. 2017;119:58-72.

Butet A, Michel N, Rantier Y, Comor V, Hubert-Moy L, Nabucet J, Delettre Y. Responses of common buzzard (Buteo buteo) and Eurasian Kestrel (Falco tinnunculus) to land use changes in agricultural landscapes of Western France. Agr Ecosyst Environ. 2010;138:152-9.

De Cáceres M, Jansen F. "Indicspecies"R Package_-Functions to assess the strength and significance of relationship of species site group associations. 2016.

De Caceres M, Sol D, Lapiedra O, Legendre P. A framework for estimating niche metrics using the resemblance between qualitative resources. Oikos. 2011;120:1341-50.

Divisek J, Zeleny D, Culek M, Stastny K. Natural habitats matter: determinants of spatial pattern in the composition of animal assemblages of the Czech Republic. Acta Oecol. 2014:59:7-17.

Ferrer M. The Spanish imperial eagle. Barcelona: Lynx Edicions; 2001.

Gotelli N, Hart E, Ellison A. Package "EcoSimR"—Null model analysis for ecological data. R Package. 2015.

Hakkarainen H, Mykrä S, Kurki S, Tornberg R, Jungell S. Competitive interactions among raptors in boreal forests. Oecologia. 2004;141:420-4.

Jaksic FM, Braker HE. Food-niche relationships and guild structure of diurnal birds of prey:competition versus opportunism. Can J Zool. 1983;61:2230-41.

Janžekovi F, NovakT. PCA - a powerful method for analyze ecological niches. In: Sanguansat $P$, editor. Principal component analysis-multidisciplinary applications. Rijeka: InTech; 2012. p. 212.

Jiménez B, Merino R, Abad E, Rivera J, Olie K. Evaluation of organochlorine compounds (PCDDs, PCDFs, PCBs and DDTs) in two raptor species inhabiting a mediterranean island in Spain. Environ Sci Pollut R. 2007;1:61-8.

Kempe S, Dirks K. Layla Lakes, Saudi Arabia: the world-wide largest lacustrine gypsum tufas. Acta Carsol. 2008;37:7-14. 
Lima SL, Dill LM. Behavioral decisions made under the risk of predation: a review and prospectus. Can J Zool. 1990;68:619-40.

Lovari S, Pokheral CP, Jnawali SR, Fusani L, Ferretti F. Coexistence of the tiger and the common leopard in a prey-rich area: the role of prey partitioning. J Zool. 2015;295:122-31.

Magurran A. Measuring biological diversity. Oxford: Blackwell Science; 2004

Naoroji R. Birds of prey of the Indian subcontinent. London: Christopher Helm; 2006. p. 692.

Norris K, Pain DJ. Conserving bird biodiversity general principles and their application. Cambridge: Cambridge University Press; 2002.

Orians GH, Soulé ME. Whither conservation biology research? Conserv Biol. 2001;15:1187-8

Oro D, Pérez-Rodríguez A, Martínez-Vilalta A, Bertolero A, Vidal F, Genovart M. Interference competition in a threatened seabird community: a paradox for a successful conservation. Biol Conserv. 2009;142:1830-5.

Pande SA, Pawashe A, Mahajan M, Mahabal A, Joglekar C, Yosef R. Breeding biology, nesting habitat, and diet of the Rock Eagle Owl (Bubo bengalensis). J Raptor Res. 2011;45:211-9.

Pande SA, Zduniak P, Yosef R. Nest occupancy and reproductive success of a subspecies of the Peregrine Falcon, The Black Shaheen (Falco peregrinus peregrinator) in Western India. J Raptor Res. 2017;51:470-5.

Development Core Team R. R: A language and environment for statistical computing. Vienna: R Development Core Team; 2017.

Rebollo S, Martínez-Hesterkamp S, García-Salgado G, Pérez-Camacho L, Fernández-Pereira JM, Jenness J. Spatial relationships and mechanisms of coexistence between dominant and subordinate top predators. J Avian Biol. 2017:48:1226-37.
Restani M. Resource partitioning among three Buteo species in the Centennial Valley, Montana. Condor. 1991;93:1007-10.

Roychowdhury K, Jones S, Arrowsmith C. Assessing the utility of DMSP/OLS night-time images for characterizing Indian urbanization. Shanghai Urban Remote Sens Event Joint. 2009. https://doi.org/10.1109/ URS.2009.5137620.

Sanchez-Zapata JA, Carrete M, Gravilov A, Sklyarenko S, Ceballos O, Donazar JA, Hiraldo F. Land use changes and raptor conservation in steppe habitats of Eastern Kazakhastan. Biol Conserv. 2003;111:71-7.

Sarà M, Mascara R, Lopez-Lopez P. Understanding the coexistence of competing raptors by Markov chain analysis enhances conservation of vulnerable species. J Zool. 2016;299:163-71.

Schoenert W. Resource partitioning in ecological communities. Science. 1974;185:27-39.

Sergio F, Blas J, Forero M, Fernández N, Donázar JA, Hiraldo F. Preservation of wide-ranging top predators by site-protection: black and red kites in Doñana National Park. Biol Conserv. 2005;125:11-21.

Stefănescu MD, Olaru ML, Babalean FA. Habitat niche overlap of raptors assemblage in the south of Oltenia region (community level analysis). Nat Montenegrina. 2013;12:387-94.

Tikader BK, Bastawade DB. Fauna of India: scorpions, Scorpionidae, Arachnida, vol. 3. Calcutta: Zoological Survey of India; 1983.

Tikader BK, Sharma RC. Handbook of Indian lizards. Calcutta: Zoological Survey of India; 1992.

White MJ. Segregation and diversity measures in population distribution. Popul Index. 1986;52:198-221.
Ready to submit your research? Choose BMC and benefit from:

- fast, convenient online submission

- thorough peer review by experienced researchers in your field

- rapid publication on acceptance

- support for research data, including large and complex data types

- gold Open Access which fosters wider collaboration and increased citations

- maximum visibility for your research: over 100M website views per year

At BMC, research is always in progress.

Learn more biomedcentral.com/submissions 